\title{
IDOSO COM DEFICIÊNCIA INTELECTUAL: ENVELHECIMENTO, DEFICIÊNCIA, ENSINO E REABILITAÇÃO
}

Karina Silveira de Almeida Hammerschmidt; Departamento de Enfermagem da Universidade Federal do Paraná (UFPR); ksalmeidah@ufpr.br;

Lisiane Capanema Silva Bonatelli; Departamento de Enfermagem da Universidade Federal de Santa Catarina (UFSC); licapanema@gmail.com;

Soraia Dornelles Schoeller; Departamento de Enfermagem da Universidade Federal de Santa Catarina

(UFSC); soraia.dornelles@ufsc.br;

Juliana Balbinot Reis Girondi; Departamento de Enfermagem da Universidade Federal de Santa Catarina

(UFSC); juliana.balbinot@ufsc.br;

Susanne Elero Betiolli; Departamento de Enfermagem da Universidade Federal do Paraná (UFPR); susanne@ufpr.br;

Giordanna Nayara Chagas e Silva; Departamento de Enfermagem da Universidade Federal do Paraná (UFPR); giordanna@ufpr.br;

Jordelina Schier; Departamento de Enfermagem da Universidade Federal de Santa Catarina (UFSC); jordelina.schier@gmail.com

\section{RESUM0}

Introdução: As Nações Unidas apontam que um bilhão de pessoas vivem com deficiência (isso significa uma em cada sete pessoas no mundo). No Brasil, dados do Instituto Brasileiro de Geografia e Estatística, aponta que 6,2\% da população brasileira tem algum tipo de deficiência. Objetivo: refletir sobre os idosos com deficiência intelectual a partir dos conhecimentos científicos produzidos sobre envelhecimento, deficiência, ensino e reabilitação. Método: Pesquisa nas bases de dados: Análise de Literatura Médica e Sistema de Recuperação Online, SCOPUS, Web of Science, Biblioteca Eletrônica Científica Online e Literatura Latino-Americana e do Caribe em Ciências da Saúde, os termos de pesquisa: "idosos ou idosos", "incapacidade", "ensino" e "reabilitação", como descritores ou palavras. Resultados: Surgiram 839 artigos, porém 392 foram excluídos por não serem artigos completos, resultando em 447. Desses 104 foram publicados na última década, nove continham no título as palavras deficiência e idosos OU incapacidade e envelhecimento e sete estavam disponíveis na íntegra. Os artigos abordam temas com temas variados: solidão, fragilidade e intensidade do atendimento, modelos de moradia e apoio, necessidades de assistência social e de saúde no serviço comunitário, satisfação do cuidado e bem-estar dos cuidadores, porém em nenhum deles destacou questões relacionadas ao ensino como um processo de (re) capacitação. Conclusão: É necessário qualificar o atendimento especializado ao idoso com deficiência, bem como fornecer apoio e orientação aos cuidadores familiares; e repensar os critérios sociais que classificam os idosos, apenas pelo aspecto cronológico, pois na deficiência intelectual, o envelhecimento é precoce.

Palavras-chave: Envelhecimento; Idoso; Incapacidade; Ensino; Reabilitação. 